2018-03

\title{
'Constructive tensions' in resilience research: critical reflections from a human geography perspective
}

\section{Wilson, GA}

http://hdl.handle.net/10026.1/10002

10.1111/geoj.12232

The Geographical Journal

Wiley

All content in PEARL is protected by copyright law. Author manuscripts are made available in accordance with publisher policies. Please cite only the published version using the details provided on the item record or document. In the absence of an open licence (e.g. Creative Commons), permissions for further reuse of content should be sought from the publisher or author. 
"This is the author's accepted manuscript. The final published version of this work (the version of record) is published by [Wiley] in [Geographical Journal 2017] available at: [DOI 10.1111/geoj.12232 ]This work is made available online in accordance with the publisher's policies. Please refer to any applicable terms of use of the publisher."

\title{
'Constructive tensions' in resilience research: critical reflections from a human geography perspective
}

\author{
Geoff A. Wilson, SOGEES, University of Plymouth, PL8 1AL, \\ geoff.wilson@plymouth.ac.uk
}

\begin{abstract}
This review paper critically examines four 'constructive tensions' in current resilience research, the first three of which are: its association with the roots of the resilience concept in ecological research; issues surrounding resilience as a normative or neutral concept; and confusion about the often interchangeable use of 'resilience' and 'sustainability' as possibly synonymous terms. The paper refers to these ambiguities as constructive tensions which have sparked fruitful discussions and debates. A fourth constructive tension is directly associated with human geography's engagement with resilience, especially by addressing the relative aspatiality of 'mainstream' resilience research, by reinforcing the importance of power and agency in resilience processes, and by arguing that resilience is strongly associated with neoliberal pathways of development. The discussion highlights that much ambiguity remains surrounding some of the key concepts associated with what makes a system 'resilient'. This means that philosophical, moral and epistemological differences in natural-science-led and social-science-led resilience research need to be continuously acknowledged, and that mainstream resilience researchers can greatly benefit from critical insights offered by human geographers.
\end{abstract}




\section{Introduction}

The notion of 'resilience' has gained substantial momentum over the past 20 years and has now gelled into an important multidisciplinary field of research spanning a variety of theoretical and conceptual positions (e.g. Adger, 2000; Grove, 2013; Anderson, 2015; Cutter, 2016; Robinson and Carson, 2016). This has led authors such as Walker and Cooper (2011, 144) to suggest that "the concept of resilience is becoming a pervasive idiom of global governance". As part of multidisciplinary approaches to resilience, geographers have played a pivotal role in shaping resilience research, with seminal contributions by Adger (2000) on 'social resilience', Martin (2012) on 'regional economic resilience', Wilson (2012) on 'community resilience', a recent intervention by Brown $(2014,2015)$ on conceptual issues of resilience from a human geography perspective, Grove's (2013) critical analysis of resilience politics, Joseph's (2013) notion of resilience as embedded neoliberalism, and a critical study by Rigg and Oven (2015) on notions of 'liberal resilience', to name but a few.

Building on critical commentators such as Adger (2000), Folke (2006), Davidson (2010) and Miller et al. (2010), this article will critically reflect upon key issues related to resilience research through a focus on what I term 'creative tensions' - i.e. positive tensions perceived as crucially important discussions and debates in a still emergent research field seen by many as under-theorised. Three key tensions will be identified (see below) that include viewpoints on resilience from various disciplinary vantage points, while a fourth tension will be discussed in relation to the specific role that human geographers have played in challenging some of the inherent notions of resilience. This study will investigate how human geographers can help resolve these tensions and whether there are theoretical and conceptual resilience frameworks that may be unique to human geography approaches. To differentiate between geography and non-geography contributions I will use the notion of 'mainstream' 
resilience research to contrast with debates on resilience in human geography, all the while acknowledging that mainstream resilience research is itself fractured, and characterised by multi- and inter-disciplinarity where commentators rarely speak with one common voice.

First, and echoing multidisciplinary debates in resilience research since the late 1990s (e.g. Adger, 2000; Davidson, 2010; Grove, 2014), there is a continuing tension between those advocating that resilience concepts emerging from earlier ecology-focused resilience research can be used and adapted to understand the resilience of 'social-ecological systems', and those suggesting that to understand the resilience of human systems (social resilience) we need to invoke different concepts and theories that are more suited to identifying the non-linear pathways of change predicated on learning and the importance of social memory. Second, a key tension revolves around the notion of resilience as a normative concept, where resilience is often portrayed as a spectrum from 'strong' resilience to 'weak' vulnerability, versus conceptualisations of resilience as either 'good' or 'bad' - i.e. resilience as a 'neutral' nonnormative and non-directional term (e.g. processes related to resilient negative pathways such as a 'resilient dictatorship'). Third, the notion of 'resilience' is often used implicitly rather than explicitly, with an underlying assumption that talking about issues such as 'sustainability' is synonymous with talking about 'resilience' processes per se. Consequently, some research claiming to assess resilience processes is founded on relatively weakly conceptualised notions of what resilience is, for whom it is important, and what the 'objective' of resilience should be. Human geography contributions to resilience research can be conceptualised as a fourth constructive tension - i.e. a specific 'geographical' approach for understanding tensions in resilience research that addresses the relative aspatiality of 'mainstream' resilience research, that reinforces the importance of power and agency in resilience processes, that suggests that resilience is often used as a vector for re-asserting neoliberal political economic relations, and that suggests human geographers often do not 
share the ontological assumptions or pragmatic interests of mainstream resilience research. In this sense, the analysis will also assess whether the notion of resilience will simply remain an abstract scientific concept, or whether it actually helps solve 'real' problems facing humanity.

It is obvious that in view of this problematic and still diverse understanding of what 'resilience' means, it is difficult to provide a working definition. Nonetheless, in order to avoid misinterpretations, and building on critical commentators such as Adger (2000), Walker and Salt (2006) and Wilson (2012), in this paper, 'resilience' of human systems will be understood as the capacity of a system to absorb human/natural shocks or disturbances and reorganize while undergoing change that either retains, or develops further, essential functions, structures, identities, and feedbacks that characterise the system. It is suggested that resilience can be assessed based on the size or magnitude of the displacement the system can tolerate and yet return to, or move towards, a state where survival of the system can be maintained. For human systems, with their complex adaptive processes based on learning after a shock or disturbance, this means that a system will rarely be fully resilient at any given time, that there are "limits of resilience" (Grove and Adey, 2015, 82), and that a system can only strive towards maximising resilience (Wilson, 2012).

\section{Does contemporary resilience research need to be founded in ecology?}

Echoing debates in multidisciplinary resilience research since the late 1990s (e.g. Adger, 2000; Folke, 2006; Grove and Adey, 2015), there is a continuing tension between those advocating that resilience concepts emerging from ecologically-based resilience research can be adapted to understand the resilience of human systems; and those suggesting that to understand the resilience of human systems we need to invoke different concepts and theories 
more suited to identifying non-linear pathways of change predicated on learning, the importance of social memory, and, most crucially, addressing the issues of power and agency that have been identified by many human geographers as lacking in mainstream ecologydominated concepts of resilience (e.g. Joseph, 2013; Grove, 2014; Brown, 2014, 2015). As Walker and Cooper $(2011,144)$ emphasised, resilience research "retains definitive links to the field of ecology". These 'constructive tensions' between natural- and social sciencedominated resilience discourses reflect different epistemological traditions between natural and social science-led approaches to resilience. While the former is closely aligned with what has been termed resilience of 'social-ecological systems', with a frequent focus on natural science interpretations of ecological-biophysical resilience processes linked to Gunderson and Holling's (2002) 'panarchy' concept and to the complex systems approach (Walker and Cooper, 2011). The latter, by contrast, is more closely associated with 'social resilience' that focuses on understanding the resilience of human systems linked to complex socio-political processes (Adger, 2000; Brand and Jax, 2007; Anderson, 2015). The social resilience focus which has been strongly informed by human geography perspectives - is based on both actororiented approaches and social, political and economic processes that reflect power and scale imbalances that shape the resilience of human systems (Wilson, 2012). In this sense, social resilience is "an important component of the circumstances under which individuals and social groups adapt to environmental change" (Adger, 2000, 347).

These two schools of resilience thought have inevitably used different approaches, emphases, interpretations and methodologies to assess 'resilience', possibly best highlighted by what some have termed positivist (social-ecological) versus constructivist (social resilience) approaches (e.g. Miller et al., 2010). Indeed, and as Brown $(2014,109)$ argued from a human geography perspective, "the transference of ideas about ecological systems to the social realm is viewed as highly problematic". As a result, both schools have criticised 
each other for either under-representing the importance of ecological processes (as advocated by critics embedded in social-ecological epistemologies such as Gunderson and Holling, 2002), or for under-estimating the importance of power and agency for understanding resilience in human systems (as advocated by critics embedded in social resilience epistemologies such as Davidson, 2010, or Brown, 2014).

Possibly most importantly, critics of the social-ecological systems approach to resilience have highlighted that recovery and adaptive capacity in human systems take on very different pathways from those in ecological systems, with notions of social capital and memory, institutional capacity, power, agency, governance, path dependencies and lock-ins being particularly important - notions that suggest that returning to an 'original'/'pre-disturbance' state is most often not the most likely or even appropriate recovery strategy for human systems (see Wilson, 2012, 2014). As Miller et al. (2010,3) highlighted, "there is a growing recognition that the persistence of certain social and economic conditions hampers positive long term [resilience]", but that too often "in the resilience literature ... empirical work is still interpreting resilience in the narrow sense of return time and recovery, thereby missing the broader use of the concept" (p.4). Similarly, Brown (2014, 109) emphasised the 'depoliticised' nature of most resilience research and "the failure to recognize resilience as socially contingent, rarely addressing the question of 'resilience for whom?"” and "that resilience fails to take account of politics and power relations" (see the discussion below). Gotham and Campanella $(2011,2)$ similarly argued that a focus on social resilience suggests that "rather than viewing humans as outside or apart from ecosystems, humans are agents of change acting within social-ecological systems". In other words, persistence, adaptability and transformability take very different forms and pathways in ecological systems compared with human systems (Walker and Salt, 2006; Grove, 2014), with the critical literature increasingly suggesting that human systems can never be fully resilient (Wilson, 2015). Brand and Jax 
(2007, 12), thus, argued that "the original ecological dimension of resilience is about to vanish". Brown's (2014) recent analysis has similarly revealed a marked upward trend in social science publications on resilience, with interesting new insights offered from human development and psychology perspectives (e.g. Wilson, 2015). Similarly, Brand and Jax (2007, 12) suggested that "recent studies increasingly stress the social, political, and institutional dimensions of resilience".

Despite these encouraging trends, ecologically-based understandings of resilience predicated on 'panarchy' and positivist, natural scientific ecological approaches are still in vogue, although refreshing new approaches are emerging in investigations of the resilience of human systems with regard to social processes and especially under-researched notions of power and agency (e.g. Grove, 2013). Acknowledgement of the important notions of power and governance particularly enables resilience to provide a bridging concept between biophysical systems and governance principles that can help to define more sustainable futures for social-ecological systems. As Joseph (2013) argued, facilitating sustainability should involve the development of new models of law that merge concepts of ecological resilience with social processes that are viewed as legitimate, equitable and just by the participants in a democratic society, rightly recognising the need for pragmatic linkages between current governance systems and new approaches that focus increasingly on interdisciplinary research across the natural/social science divide. Achieving this level of integration between ecological concepts and governance, thus, requires a dialogue across multiple disciplines, including ecologists, climate experts, social scientists, and political and legal scholars. Nonetheless, Miller et al. (2010, 1-2) have suggested that "taken singly, each approach and each research community has so far fallen short of meeting the needs of [resilience research]" and that, most importantly, "theoretical approaches and practical applications proposed by either community often do not refer to work of the other 
community", with only a few signs of conceptual and empirical collaboration. Such studies suggest that resilience research has hitherto been more strongly influenced by positivist 'social-ecological' epistemologies, while constructivist social resilience approaches have only recently gained momentum based on increasing recognition that resilience of any system can only be understood with detailed and 'deep' understanding of power, agency, perceptions, values and cultural differences that play crucial roles in implementing resilience pathways in human systems.

Thus, while some researchers advocate that the solution lies in closer collaboration between academic communities (e.g. Miller et al., 2010), I (as a human geographer) would advocate that, first and foremost, more focus needs to be placed on acknowledging the importance of agency and power in research that focuses on understanding the resilience of human systems (see the fourth 'constructive tension' discussed below) - even for research under the umbrella of 'social-ecological' systems approaches (see also Davidson, 2010). As Adger (2000) and Brown (2014) have highlighted, the key here is to analyse the nature of agency and governance as important drivers for resilience issues in a politically nuanced way, and through hybrid and mixed methodologies that also allow investigation of 'deep' sociopolitical processes, and that acknowledge the non-linear and heterogeneous nature of resilience pathways. In particular, researchers embedded in the social-ecological resilience paradigm need to acknowledge more that human systems can never 'bounce back' to a predisturbance state, as social memory and learning processes mean that new resilience pathways emerge that may build on previous pathways and memories that are often also qualitatively different and may include unanticipated 'surprise adaptations'. Thus, "the challenge from a [social] resilience perspective is to learn to live with change and develop the capacity to deal with it instead of trying to block it out" (Miller et al., 2010, 5). The social resilience approach, therefore, also acknowledges that no human system can ever be fully 
resilient, and that some components of the system (e.g. a weak stakeholder group) may still be vulnerable. It is in these resilience research arenas, in particular, that fruitful opportunities emerge for human geographers, as they are able, more than other disciplines, to provide a critical bridge between discussions on how space and scale, governance, power and complex socio-economic processes affect the resilience of human systems.

\section{Resilience as a normative or neutral concept?}

Second, a key tension in many publications on resilience revolves around notions of resilience as either a normative or a neutral concept - another key arena in which human geographers can make a particular contribution. This distinction reflects the different epistemological traditions of those focusing on resilience from a social-ecological systems perspective (often with a natural science/ecological focus; see above), as opposed to social science approaches focusing on the resilience of human systems (e.g. Adger, 2006; Davidson, 2010; Grove and Adey, 2015).

A normative approach is based on the assumption that resilience can be situated along a spectrum from 'good' resilience to 'bad' vulnerability, where resilience-vulnerability are seen as oppositional terms and where resilience is a desirable or better state or outcome. This notion has been supported by several authors including many human geographers (e.g. Janssen and Ostrom, 2006; Miller et al., 2010; Duffield, 2012). Schmidt (2013, 175), for example, argued that "resilience is accorded with a positive connotation" and is seen "as a normative goal" (p. 191), and Grove $(2014,244)$ similarly suggested that "resilience is a progressive development in research and policy on hazard and vulnerability reduction ... it seeks to empower people to be agents of their own vulnerability reduction". Resilience is, 
thus, often associated with the 'quality' of a system under investigation, with resilience as a normative process or outcome from human action (Adger, 2000; Brand and Jax, 2007).

This normative view suggests, therefore, that 'weak resilience' does not exist (it is, in fact, 'vulnerability'). Walker and Salt (2006, 9-10), thus, argued that to ignore change associated with resilience processes "is to increase our vulnerability", while Gotham and Campanella (2011, 2; emphasis added) argued similarly that "we can understand the concepts of resilience and vulnerability only in relation to one another since both are properties of a social-ecological system". There is a clear link to constructivist notions of social resilience in these arguments as only human systems are ascribed either 'good' or 'bad' attributes based on the positionality of researchers/commentators. As both Adger (2006) and Miller et al. (2010) have highlighted, the notion of vulnerability emerges from a social-political conceptualisation of resilience. This normative approach implies, again, that human systems can never be fully resilient as they always contain certain elements/processes that contribute to vulnerability (Wilson, 2012).

An opposing view is that resilience is a neutral and non-directional concept that can be either 'good' or 'bad'. This is best illustrated by pathways that seem 'resilient' but that most commentators would perceive as negative for the long-term survival and adaptive capacity of a system, such as a 'resilient' dictatorship or 'resilient' lock-in processes associated with extreme income disparities, unequal power and governance structures, neo-liberal pathways, capitalism, neo-colonialist processes, or entrenched environmental degradation processes (Walker and Cooper, 2011; Baird et al., 2017). Grove and Adey $(2015,82)$ thus argued that "resilience has no constitutive power of its own", suggesting that resilience in itself can and should not be directional, while Walker and Cooper $(2011,156)$ argued with reference to 'rigidity traps' and 'too resilient societies' that some human systems "have become so internally integrated that they are now resistant to perturbation - unable to change in the face 
of shocks that can be as creative and generative as they are destructive". Thus, resilience is often equated with 'persistence' of a system attribute and, consequently, as a 'neutral' emergent system property - notions often rooted in natural science/ecological conceptualisations of resilience (Brand and Jax, 2007; Miller et al., 2010). This more positivist view relates to resilience as a seemingly 'neutral' ecological phenomenon where non-normative processes dominate; that is, its processes have no 'value' definable as 'good' or 'bad' (Gunderson and Holling, 2002).

However, in recent years the view of resilience as a normative concept has been endorsed by many key commentators and organisations (e.g. Levin et al., 2012; OECD, 2013). In these studies, the vulnerability terminology is generally rooted in natural disaster/hazard studies in the geophysical sciences, human ecology, political economy and political ecology but with a strong focus on the vulnerability of human systems (Miller et al., 2010). Echoing Brown's (2014) argument for a 'social turn' in resilience approaches and more societally relevant research on resilience, it would, therefore, appear that the normative view of resilience is gradually gaining ground, associated with the increasing inclusion of resilience approaches grounded in the social sciences (Miller et al., 2010).

As a result, Adger $(2000,348)$ saw resilience as "a loose antonym for vulnerability" while Folke $(2006,262)$ argued that "a vulnerable social-ecological system has lost resilience", emphasising that this normative view of resilience focuses on enhancing coping processes that reduce vulnerability to human health risks, livelihoods and community survival. Miller et al. $(2010,1)$ meanwhile, argued that the two concepts "have been kept artificially separate by conceptual constructs, scientific traditions, and lack of interaction between ... academic communities involved", but that "a combination of the processes of economic liberalization, climate change, and other environmental dynamics have been shown to interact with sociopolitical factors to influence human vulnerability" (p.4). The $\operatorname{OECD}(2013,7)$ similarly 
associated resilience with notions of 'good practice' in its landmark publication 'Risk and resilience: from good idea to good practice' and advocated that resilience must be understood along a spectrum of decision-making ranging from resilience to vulnerability, so that "achieving a resilient community requires vulnerability reduction". This suggests that development practitioners, in particular, often view vulnerability and resilience as two sides of the same coin where more of the former means less of the latter, and where certain processes erode resilience to shocks or disturbances by accentuating pre-event vulnerabilities (e.g. Janssen and Ostrom, 2006). Brown (2014) argued that probably the most evident use of resilience as a normative concept from a 'practical' perspective is in the burgeoning transition towns movement where resilience is used as a 'positive' and 'directional' central organising principle as a core normative objective for community and individual transitions. This vision acknowledges that resilience has a 'dark side', i.e. that vulnerability has to be part-and-parcel of resilience conceptualisations as the antithesis of 'positive' resilience.

Nonetheless, a review of the resilience literature suggests that it is not always obvious whether authors are referring to resilience as normative or neutral. In line with Miller et al. (2010) more clarity is, therefore, needed in future resilience research. Echoing many other critical commentators (e.g. Miller et al., 2010; Davidson, 2010; Levin et al., 2012) I wish to support the case for resilience as a normative concept - i.e. where 'resilience' is seen as the opposite of 'vulnerability' along a spectrum that helps pinpoint the state of a system under investigation. The key justification for this position is that resilience as a neutral concept loses much relevance as a possible basis for human decision-making, especially with regard to identifying policies that aid human systems to become more 'resilient'. As Miller et al. $(2010,14)$ argued, "the complexity of the concept of resilience and the multidisciplinary nature of resilience assessment form significant institutional barriers to the application of resilience thinking by policy makers". In other words, resilience as a neutral process is too 
fuzzy to provide clear guidelines for changing human actions through policies, while resilience as a normative notion chimes better with the clarity and direction that policymakers and humanitarian organisations need in order to address vulnerable human systems (e.g. OECD, 2013). Most importantly, as Wilson (2012) argued, a normative notion of resilience allows recognition of the importance of social memory and social learning processes in building resilience.

More clarity with regard to the interlinkages between resilience and vulnerability is, therefore, important, as attempting to make a system more resilient in a particular way may inadvertently result in increased vulnerability, for example by strengthening the role/power of specific community stakeholders, and potentially leading to increased vulnerability for other stakeholders. As Levin et al. $(2012,2)$ argued, the notion of resilience as a neutral emergent property "encourages value-free analysis by focusing on outcomes and symptoms of resilience, [but] avoiding looking at the power relations that are at the root of much vulnerability". Thus, only a normative resilience concept that sees resilience as a positive goal to be achieved will allow directional policy-making that aims at reducing vulnerability. Both Brand and Jax (2007) and Eakin and Webbe (2009) argued that a normative view of resilience, therefore, enables goal-setting with regard to specific 'positive' resilience attributes, allows for stepwise and iterative implementation of resilience-related policies, and permits a resilience-based rhetoric that can be used to persuade stakeholders to change their behaviour. Miller et al. (2010) nonetheless emphasised that a normative view of resilience needs to be robust with regard to the application of a resilience-vulnerability spectrum to concepts, theories and methodologies that address real-world problems in practice. By contrast, resilience as a neutral concept precludes directional goal setting (as no-one would want to advocate 'negative' resilience attributes), does not provide clear guidelines or thresholds for policy-makers to find solutions to improve systems, and precludes the sending 
of a clear message to stakeholders with regard to preferred pathways. This means that only a directional, goal-oriented, normative notion of resilience can help (human) systems become 'more resilient', and provide the foundation for helping solve real problems facing humanity.

\section{Implicit and explicit uses of the notion of 'resilience': does resilience = sustainability?}

Third, and equally important, the notion of 'resilience' is often used implicitly rather than explicitly in many resilience studies. There is a frequent underlying assumption that talking about issues such as 'sustainability' or 'development' is synonymous with talking about resilience, leading to a perception that research claiming to assess resilience processes rests on relatively weak conceptualisations of what resilience is, for whom it is important, and what its 'objectives' are.

Many commentators agree that there is a "connection between resilience and sustainability" and that "the relevance of the [resilience] concept for the problem of sustainable development has been recognised for at least fifteen years" (Perrings, 2006, 417).

It is generally assumed, therefore, that notions of sustainability and resilience share many conceptual and epistemological themes including the idea of thresholds, path dependencies and complex transitional processes characterised by non-linearity (Wilson, 2012). Indeed, Perrings $(2006,418)$ suggested that "a development strategy is not sustainable if it is not resilient", although he also conceded that research on the interlinkages between "resilience and sustainability is at a relatively early stage of development" (p. 422).

There are different positions on the complex interlinkages between 'sustainability' and 'resilience', two notions that have been discussed since Greek philosophy in the first millennium BC (Wilson, 2012). This longevity might lead us to question the novelty of resilience processes, that may just be 'minor changes' in a long-standing logic of 
preparedness (Anderson, 2015). However, in academic debates both are relatively recent, albeit with 'sustainability' having evolved from an academic context in the 1980s and 1990s to a practical and policy-relevant notion in the last 20 years, while 'resilience' has a shorter academic history in its application to human systems, and remains more rooted in academic theory and concepts that may seem somewhat opaque (Miller et al., 2010; Anderson, 2015). Nonetheless, a more applied, practitioner-led, use of resilience is now emerging from its academic conceptualisation, with the associated risk of 'resilience' becoming a catchall in the same way that sustainability has. As a result, some commentators see little difference between the two and are rather critical of both concepts as relatively shallow, fuzzy and overly broad academic concepts with little meaning and policy relevance (e.g. Anderson, 2015; see also Reid, 2012, on the 'disastrous and politically debased subject of resilience'). Brand and Jax $(2007,10)$ similarly argued that the meaning of both 'resilience' and 'sustainability' "is highly diluted and unclear" and that both catchwords enable "different scientific disciplines or social groups to justify their particular interests with respect to an accepted ... goal". More positively, however, Brown $(2014,114)$, after an extensive review of the literature, has argued that "resilience is similar to sustainability, in that the very malleability and plasticity of the term itself means that it can act as a boundary object or bridging concept".

Others, however, see subtle differences between the two concepts, and these fall into two general groups. First, there are advocates who argue that sustainability continues to provide an overarching concept that includes consideration of resilience pathways as crucial components of a transition towards a more sustainable society (e.g. Perrings, 2006). Shaw (2012), for example, saw resilience as extending the sustainable development agenda, while Eakin and Webbe (2009) viewed notions of 'resilience' and 'sustainability' as equally valuable terms. Brand and Jax $(2007,1)$ meanwhile argued that "the concept of resilience is 
one of the most important research topics in the context of achieving sustainability" - i.e. systems cannot be sustainable without at least some pathways of resilience and the embeddedness of resilience within broader 'sustainability science'. In fact, as early as the 1990s, several commentators had begun to argue that resilience was an important tool for measuring sustainability (Adger, 2000).

Second, some argue that the notion of resilience has now become so all-encompassing that it is beginning both to subsume sustainability trajectories as a crucial ingredient for a resilient human system, and even to supersede sustainability as resilience-related concepts render sustainability redundant. Building on this, resilience can be seen as contributing to a move away from conventional notions of sustainability, with sustainable development as one of many potential pathways that a system may follow. In this view, a sustainable development trajectory is the outcome of a resilient community. Perrings (2006, 425, emphasis added), for example, suggested that "sustainable development ... requires that the value of the asset base available to the relevant population does not decline over time [while] a resilience perspective implies that the composition of the asset base is critically important". Similarly, Brassett et al. (2013, 222; emphasis in original) argued that "resilience is fast becoming the organising principle in contemporary political life" and "the rationality of resilience begins to take on an inevitability and universality" (p. 225), suggesting that resilience is encompassing other notions such as sustainability - a process referred to as 'creeping colonisation' of resilience terminology by Grove and Adey (2015). As Brand and Jax (2007) argued, it is this malleability and fuzziness of both 'sustainability' and 'resilience' that has made them attractive concepts for various stakeholder groups, practitioners, policymakers and academics, but that is also the cause for much misuse of both terms. As a result, many articles on resilience address resilience themes rather than notions of resilience. Often there is an implicit assumption that topics touching on sustainability issues will, inevitably be 
relevant for the analysis of resilience, and some authors assume that by addressing issues of sustainability, positive benefits for system resilience automatically follow. This implies that more clarity of discussion about connections between sustainability and resilience is urgently needed.

Human geography and resilience: space/scale, power, and the critique of resilience as a neoliberal project

The discussion above has highlighted the important contributions of human geographers in challenging the early predominance of ecology-centric approaches to resilience (e.g. Adger, 2000; Davidson, 2010); to debates on the normativity of resilience (e.g. Wilson, 2012; Brown, 2014); and to discussions about the interlinkages between resilience and sustainability (e.g. Brand and Jax, 2007; Brassett et al., 2013). Indeed, there has been a considerable growth in writing on resilience from a human geography perspective in recent years. A fourth constructive tension in resilience research is, therefore, directly related to the role human geographers have played in challenging 'mainstream' resilience concepts through their critique of ontological, epistemological and ethical presuppositions inherent in mainstream resilience research. Three key human geography contributions stand out in this respect: linkages of resilience concepts to issues of space and scale; the call for a better understanding of notions of power in resilience; and, possibly most importantly, the critique of the mainstream notion of resilience as a neoliberal project.

First, it is evident that human geographers have been best placed to address notions of scale and space in resilience research. The focus on spatial approaches to resilience research by human geographers is a direct critique of the often aspatial conceptualisation of resilience 
in mainstream resilience research, and characteristic of resilience concepts developed in disciplines such as psychology, sociology and history. Indeed, Massey (2005) highlighted how human geography, through its specific spatial, scalar and multi-dimensional focus, has something unique to contribute to integrative research which, as the three 'constructive tensions' discussed above have highlighted, is also a characteristic of research on resilience. Ranging from Wilson's (2012) notions of 'nested spatial hierarchies' of resilience and conceptualisations of the complex spatiality of resilience transitions, to Davidson's (2010) incisive critique of aspatial and apolitical approaches used by mainstream resilience research, to Martin's (2012) focus on regional resilience as a key spatial analytical level, human geographers have highlighted that resilience-building processes are spatially heterogeneous, temporally complex and never uni-linear. From a scalar and methodological perspective, human geography resilience research has particularly highlighted that resilience and vulnerability pathways are easier to understand at the individual and local levels (Wilson, 2012, 2015), difficult to grasp at the regional level (Martin, 2012), and methodologically, ontologically and epistemologically almost impossible to understand at the global level as too many factors have to be considered that make up the 'mix' of components of a globally resilient system (Wilson, 2014; Brown, 2014, 2015). Human geographers have thus provided an explanation as to why much resilience research has focused on 'community resilience' ranging from small-scale village communities to larger scale urban communities.

Apart from the fact that resilience processes and pathways are spatially uneven, human geography research has also shown that different stakeholder groups are also affected by, and in turn affect, resilience pathways in spatially and temporally complex ways. Thus, while mainstream resilience research often sees resilience as an end in itself or as an outcome of action that assumes consensus on a desired state for a resilient system, human geographers have highlighted that social resilience is multi-layered and fractured, with some stakeholder 
groups more resilient than others (Wilson, 2012; Grove, 2013; Anderson, 2015). This arises because systems that are resilient at one spatial scale may not be resilient at others; what may seem a 'resilient' system for some stakeholders may not be resilient for all; and resilience trajectories usually only benefit some stakeholders.

Human geography's second major contribution revolves around the constructivist argument that resilience of human systems cannot be understood without understanding the role of power in resilience processes (e.g. Joseph, 2013; Grove, 2014; Brown, 2014, 2015). The social resilience focus - which has been strongly informed by human geography (cf. Adger, 2000) - is based on both actor-oriented approaches and social, political and economic processes that reflect the power and scale imbalances that shape resilience in human systems (Wilson, 2012). Yet, constructivist social resilience approaches in human geography have only recently gained momentum through increasing recognition that resilience must be understood with detailed, 'deep' understanding of power, agency, perceptions, values and cultural differences that play crucial roles in implementing resilience pathways in human systems. Understanding these deep socio-cultural aspects of resilient systems requires hybrid and mixed research methods to uncover the nature and roles of agency, politics and governance as drivers of resilience (Wilson, 2014; Brown, 2014).

Acknowledgement of the importance of power and agency in resilience research is therefore necessary across the disciplinary landscape. Walker and Salt (2006) and Walker and Cooper (2011), for example, saw resilience as a vector for power relations and have provided a deeper understanding of the forms of power that operate within contemporary societies to shape thoughts, beliefs, actions and resilience pathways. The voices of human geographers have been important in strengthening existing critiques of often simplistic and apolitical resilience concepts adopted in mainstream resilience research (see Grove, 2013; Anderson, 2015). Inevitably it has proven difficult for ecological approaches to account for power and 
agency, but, as Davidson (2010) and Brown (2014) have particularly highlighted, even resilience research under the umbrella of 'social-ecological systems approaches' have often underestimated the roles that power and agency play in making systems more resilient or vulnerable. By directly criticising such mainstream resilience approaches, human geographers have highlighted that recovery and adaptive capacity in human systems take on very different pathways from those in ecological systems, with notions of social capital and memory, institutional capacity, power, agency, governance, path dependencies and lock-ins particularly important - notions that suggest that returning to an 'original'/'pre-disturbance' state is most often not the most appropriate recovery strategy for human systems (Wilson, 2012, 2014). As a result, there is an important link here between geographers' call for an increased focus on notions of power in resilience research and the issue of normativity highlighted above. Indeed, by highlighting the complex interlinkages between issues of space, scale, governance and socio-economic processes, human geographers have been ideally placed to contribute substantially towards normative assessments of resilience and vulnerability processes (Grove, 2013; Anderson, 2015; Rigg and Oven, 2015).

The third contribution of human geography to resilience research is arguably its most important, namely the critique that notions of resilience are reinforcing neoliberal pathways of development. Indeed, and in line with often radical left-wing, anti-capitalist, and Marxist leanings within human geography, several commentators (e.g. Anderson, 2015) have argued that resilience can increasingly be interpreted as a neoliberal project, especially as neoliberal pathways are seen by many mainstream resilience researchers as the key to making societies more resilient. Joseph $(2013,38)$, for example, suggested that resilience "is best understood as a neoliberal form of governmentality that places emphasis in individual adaptability", and that it has "certain ontological commitments that make it ideally suited to neoliberal forms of governance". This suggests that "the move toward resilience is ... about creating resilient 
subjects that are trained to ride the unpredictable waves of neoliberal life" (Pugh, 2014, 316). As a result, some have argued that resilience is so compromised by neoliberal ideology that it should be cast aside in favour of terms with less ideological baggage such as 'resourcefulness', leading radical authors such as Reid $(2012,67)$ to refer to the "disastrous and politically debased subject of resilience". Human geographers have, therefore, argued that mainstream resilience research has tended to reinforce rather than challenge the neoliberal status quo. This means that, more than any other discipline, human geographers have placed criticisms of the global capitalist and neo-liberal systems at the heart of their critiques, suggesting that resilience has been misappropriated politically. Inevitably, this raises fundamental questions about the 'best' socio-political development pathways and, indeed, the importance of democratic processes themselves in building resilience (for example, could a political-economic system such as China's be more conducive to developing resilient pathways than that of 'ultra'-neoliberal countries such as the UK or the USA?). As Pugh (2014) and Grove (2014) have argued, human geography can offer such an incisive critique, as most other disciplines do not analyse resilience from a spatial perspective that best highlights unequal power relations and that, therefore, can also more easily identify the dominance of neo-liberal agendas in conceptualisations of resilience.

Inevitably, there is a close link between notions of resilience as a neoliberal project and the 'constructive tension' of normativity in resilience research discussed above. Normativity in this context is seen to be an indication of the changing organisational structure of advanced liberal societies, whereby resilience is seen as not just a reactive process that induces people to 'bounce back' but that also acts as a means to create 'resilient subjects' and citizens capable of adapting to and exploiting situations of uncertainty (Pugh, 2014). In the critiques by Duffield (2012) and Grove (2014), such a normative view of neoliberal resilience foregrounds active citizenship and agency, individual preparedness, awareness, learning 
pathways, and discourses that transfer responsibility to local agents and sees neoliberal complexity and development opportunities as positive states that appear to enhance resilient pathways in human systems. Pugh (2014, 316; emphasis added) argued that, as a result, "resilience has increasingly emerged as the dominant response and governmental rationality in international intervention" - in other words, resilience is often set as a normative positive goal in international aid and politics (e.g. OECD, 2013). While such a normative goal may, in itself, not be problematic (see discussion above), human geographers have highlighted that the politically-laden normativity associated with resilience and the neoliberal project are, indeed, highly problematic and need to be both critically addressed and challenged in future mainstream resilience research.

\section{Conclusions}

This paper has set out to explore four 'constructive tensions' in current resilience research, three of which are: association with the roots of the resilience concept in ecological research; issues surrounding resilience as a normative or neutral concept; and confusion about the often interchangeable use of 'resilience' and 'sustainability' as synonymous terms. I have referred to these ambiguities as constructive tensions which have sparked fruitful discussions and debates that are a major part of taking resilience research forward. A fourth constructive tension is directly associated with human geography's engagement with resilience, especially in addressing the relative aspatiality of 'mainstream' resilience research, by reinforcing the importance of power and agency in resilience processes, and by arguing that resilience is strongly associated with neoliberal pathways of development. This highlights that much 
ambiguity remains surrounding some of the key concepts associated with what makes a system 'resilient' (Davidson, 2010).

This confusion in concepts and definitions of resilience has been criticised by many commentators, including several human geographers (e.g. Wilson, 2012; Reid, 2012; Brown, 2014; Anderson, 2015). Indeed, most human geographers would probably agree with Miller et al.'s $(2010,6)$ critique that the "tendency for each [resilience] community to redefine other communities' terms in their own language, invariably situating their own concepts on a higher ground and the other's as a derivative, may have impeded collaboration"; and with Brand and Jax's $(2007,12)$ caution that "the meaning of resilience [becomes] increasingly vague and unspecified ... [and] that both conceptual clarity and practical relevance of resilience are at stake". Anderson $(2015,60)$ similarly argued that "resilience' appears to have proliferated across multiple, at best partially connected, domains of life" and that "resilience may not only be empirically multiple but can also be very different types of things" (p.62), while Duffield $(2012,481)$ went as far as arguing that "resilience has become a monotonous characteristic of everything”. As a result, Grove $(2013,146)$ concluded that "resilience is increasingly marshalled ... to defend and strengthen the political economic status quo against uncertainty and surprise".

This review has argued that human geography is well placed to make major contributions to resilience research due to its strategic location at the intersection between several of the 'constructive tensions' highlighted above, in particular: by contributing towards 'socialising' and 'politicising' resilience research, and highlighting the crucial importance of power and politics within complex actor spaces in resilience research (Duffield, 2012; Grove and Adey, 2015); by promoting resilience as a normative term with 'real' potential for informing policymaking and changing attitudes, action and behaviour on the ground (Davidson, 2010; Rigg and Oven, 2015); and by further clarifying conceptual differences between 'sustainability' 
and 'resilience' (Adger, 2000; Davidson, 2010). In particular, human geographers have highlighted that complex interlinkages between resilience and neoliberal pathways of change need much more critical scrutiny (Grove, 2014; Rigg and Oven, 2015). Brand and Jax (2007), Miller et al. (2010) and Wilson (2012) have nonetheless highlighted that synergies are beginning to emerge with regard to responses of human systems to shocks and disturbances, interactions of slow and rapid changes (both in human and natural systems), and system and actor dynamics. What is particularly encouraging from a human geography perspective is that 'mainstream' studies are increasingly acknowledging the importance of hitherto neglected forces and processes affecting resilience, notably those linked to notions of power, space/place, agency, governance and socio-political processes.

It is evident, therefore, that human geographical views of resilience are not simply subservient to debates in ecology and other fields, but have made a distinct contribution. Indeed, the discussion above has highlighted a human geography with the intellectual capacity and breadth to offer both social and political insights in the study of resilience, especially as it does not share the same epistemological, ontological and ethical approaches for understanding resilience processes as most mainstream resilience research. By addressing notions of spatiality, power and neoliberalism and how they interlink with resilience, human geography's contribution to resilience research has raised questions that mainstream resilience scholars themselves have struggled to address. Human geographers particularly highlight resilience as a problematic concept, with adaptation as a crucial component of resilience building being partial, narrowly-defined and often reinforcing the political status quo (especially neoliberal socio-political pathways). A significant part of human geographical research adopts a stance of openly radical critique of mainstream resilience research that explicitly does not attempt to use 'resilience' as a way to understand social and ecological dynamics, but that raises crucial questions about the complex interlinkages 
between notions of power and resilience. The approach of human geographers to resilience, thus, does not simply dismiss resilience as a misguided, depoliticised or flawed concept, but instead asks whether resilience is simply a mechanism for reinforcing neoliberal rule with little potential for challenging or subverting neoliberal governance (Grove, 2013; Anderson, 2015).

The discussion in this article has thus emphasised that philosophical, moral and epistemological differences between natural-science-led and social-science-led resilience research need to be continuously acknowledged, and that mainstream resilience researchers can greatly benefit from critical insights offered by human geographers. It is, nonetheless, unlikely at this juncture that an over-arching framework for understanding 'resilience' will be found in the near future. Resilience will, therefore, continue to be a janus-faced 'boundary object' (Brand and Jax, 2007), and with inclusion of ever more disciplines into the broad arena of resilience research, further fragmentation is most likely.

\section{Acknowledgements}

Please see title page.

\section{References}

Adger W N (2000) Social and ecological resilience: are they related? Progress in Human Geography 24 (3) $347-364$

Adger N W (2006) Vulnerability Global Environmental Change 16 268-281

Anderson B (2015) What kind of thing is resilience? Politics 35 (1) 60-66 
Baird T D, Chaffin, B C and Wrathall, DJ (2017) A disturbance innovation hypothesis: perspectives from human and physical geography. The Geographical Journal 183 201-208

Brand F and Jax K (2007) Focusing the meaning(s) of resilience: resilience as a descriptive concept and a boundary object Ecology and Society 1213

Brassett J, Croft S and Vaughan-Williams N (2013) Introduction: an agenda for resilience research in politics and international relations Politics 33 221-228

Brown L (2014) Global environmental change I: a social turn for resilience? Progress in Human Geography 38 107-117

Brown, K (2015) Resilience, development and global change. London Routledge

Cutter, S L (2016) Resilience to What? Resilience for Whom? The Geographical Journal $182110-113$

Davidson, D J (2010) The applicability of the concept of resilience to social systems: some sources of optimism and nagging doubts Society and Natural Resources 23 11351149

Duffield, M (2012) Challenging environments: danger, resilience and the aid industry Security Dialogue 43 475-492

Eakin, H and Webbe M (2009) Linking local vulnerability to system sustainability in a resilience framework: two cases from Latin America Climatic Change 93 355-377

Folke, C (2006) Resilience: the emergence of a perspective for social-ecological systems analyses Global Environmental Change 16 253-267

Gotham, K F and Campanella R (2011) Coupled vulnerability and resilience: the dynamics of cross-scale interactions in post-Katrina New Orleans Ecology and Society 1612

Grove, K (2013) On resilience politics: from transformation to subversion Resilience 1 146153 
Grove, K (2014) Agency, affect and the immunological politics of disaster resilience Environment and Planning D: Society and Space 32 240-256

Grove, K and Adey P (2015) Security and the politics of resilience: an aesthetic response Politics 35 78-84

Gunderson, L H and Holling C S (eds) (2002) Panarchy: understanding transformations in human and natural systems Washington DC: Island Press.

Janssen, M A and Ostrom E (2006) Resilience, vulnerability, and adaptation: a crosscutting theme of the International Human Dimensions Programme on Global Environmental Change Global Environmental Change 16, 237-239

Joseph, J (2013) Resilience as embedded neoliberalism: a governmentality approach Resilience $138-52$

Levin, S, Pain, A, Bailey, S and Fan L (2012) The relevance of resilience? London: Overseas Development Institute (Humanitarian Policy Group brief 49).

Martin, R (2012) Regional economic resilience, hysteresis and recessionary shocks Journal of Economic Geography 12 1-32

Massey, D (2005) For space. London Sage

Miller, F, Osbahr, H, Boyd, E, Thomalla, F, Bharwani, S, Ziervogel, G, Walker, B, Birkmann, J, Van der Leeuw, S, Rockström, J, Hinkel, J, Downing, T, Folke, C and Nelson D (2010) Resilience and vulnerability: complementary or conflicting concepts? Ecology and Society 1511

OECD [Organisation for Economic Cooperation and Development] (2013) Risk and resilience: from good idea to good practice - a scoping study for the Experts Group on Risk and Resilience. Paris: OECD (working paper 13/2013) http://www.oecd.org/dac/governance-development/risk-resilience.htm (last accessed March 2017). 
Perrings, C A (2006) Resilience and sustainable development Environment and Development Economics 11 417-427

Pugh, J (2014) Resilience, complexity and post-liberalism Area 46 313-319

Reid, J (2012) The disastrous and politically debased subject of resilience Development Dialogue 58 67-80

Rigg, J and Oven K (2015) Building liberal resilience? A critical review from developing rural Asia Global Environmental Change 32, 175-186

Robinson, G M and Carson D A (2016) Resilient communities: transitions, pathways and resourcefulness The Geographical Journal 182 114-122

Schmidt, J (2013) The empirical falsity of the human subject: new materialism, climate change and the shared critique of artifice Resilience 1 174-192

Shaw, K (2012) The rise of the resilience local authority? Local Government Studies 38 281300

Walker, B and Salt D (2006) Resilience thinking: sustaining ecosystems in a changing world. Washington Island Press

Walker, J and Cooper M (2011) Genealogies of resilience: from systems ecology to the political economy of crisis adaptation Security Dialogue 42 143-160

Wilson, G A (2012) Community resilience and environmental transitions London Earthscan/Routledge.

Wilson, G A (2014) Community resilience: path dependency, lock-in effects and transitional ruptures. Journal of Environmental planning and Management 57 1-26

Wilson, G A (2015) Community resilience and social memory Environmental Values 24 $227-257$ 